\title{
World-Wide Web Sites for Second Language Learning
} Advanced Institute for Science and Technology—Japan

At the present time an increasing number of language educators are utilizing sites on the World-Wide Web ( groups of hypertext-linked pages) as a teaching resource. However locating pedagogically useful sites from the large number available can be a somewhat intimidating task. This paper will introduce a number of high-quality web sites relevant to the needs of second language learners.

Web Sites Educators must consider a number of factors when selectfor Language ing sites for classroom use, as Internet-based language learnLearning ing sites take a variety of forms. Most web pages are integrative in nature-requiring learners to use both productive and receptive language skills actively while undertaking a variety of tasks. Many of these sites are also interactive to some extent, in the sense that they are designed to enable learners to interact with either the target language or other users of the language, through such means as e-mail or through the use of chat rooms. Other web pages are designed with an emphasis on improving proficiency in one of the "four skills." An example of this last approach may be found in a web site that provides downloadable audio clips for listening practice.

The majority of web sites for second language learning are designed to meet the needs of intermediate level learners. $\mathrm{Li}$ and Hart (1996) have pointed out that it is this group which can gain the greatest benefits from web-based interactive courseware, as beginning students lack the vocabulary to undertake a wide array of web-based activities.

Technical Challenges
Hardware and software issues are also of importance. Many web sites are only designed to be used with the latest versions of Internet browsers or such sites often require special plugins to operate effectively. Users must also be aware of the network environment in which they operate. Download- 
ing large files from remote locations may present some users with unacceptable download times. Finally, educators must be aware that over time many sites change address or are removed from servers.

\section{Listening Based Web Sites} Web Sites

\section{Integrative Web Sites}

A number of web sites utilize audio files containing prerecorded synthesized speech, for listening and pronunciation practice. The most comprehensive of these sites is "LinguaCenter" maintained at the University of Illinois. The site consists of a number of hypertext links to audio-based sites including ABC Radio News, National Public Radio and World Radio Network. At sites such as NPR, audio materials are accessed through a helper application known as "RealAudio" (http://www.realaudio.com/), in order to reduce download times.

Purdue University On-Line Writing Lab focuses on most aspects of writing. The English as a second language section of this comprehensive site contains useful information relating to problem areas of usage. A number of downloadable handouts are available that are designed specifically to meet the needs of EFL and ESL learners. These include an extensive range of materials relating to grammar.

The "Hut Internet Writing Project" was conceived and developed at Helsinki University of Technology. This site was designed as part of an international writing project in which learners from various countries collaborated via the Internet. Although the project is no longer active this site provides access to a number of valuable materials. Resources at this site include a page that introduces the cultures of participants' home countries. Moreover a language help page gives access to documents on various aspects of writing including academic, business and technical writing. An innovative aspect of this site is the fact that many of the documents available are produced by EFL educators and learners. In addition the site provides access to a help page designed to assist learners overcome any technical problems they may encounter while using email.

Exchange too was established in order to provide a cross cultural forum for second language leaners (Shetzer, 1995). The site is divided into four sections covering the following areas: World Cultures, Current News and Events, Stories and the Learning Resource Center. Learners are encouraged to participate by submitting email articles relevant to the above areas. On-line editors (experienced ESL teachers) assist learners to publish these submissions after providing infor- 
"Educators must consider a number of factors when selecting sites for classroom use, as Internet-based language learning sites take a variety of forms." mative feedback. Attractive features of this site include an onscreen glossary, an English idiom databank, an on-line dictionary and a web-based reading comprehension test.

The computer-assisted language learning section of the Chorus web site is run by the University of California, Berkeley. This site makes use of the latest Shockwave multimedia players (or plug-ins) to enable users to play interactive movies and audio over the internet. These plug-ins are available for downloading at this site. Activities include two short interactive animations concerning preposition use. In addition learners may also access three interactive quizzes relative to listening comprehension and grammar-based sentence completion. Learners are prompted to provide their email addresses in order to obtain quiz results and feedback. This site must be accessed through one of the later versions of Netscape Navigator.

"Learning Oral English Online" takes the form of an online conversation book designed to assist intermediate level language learners improve their listening and speaking skills. The site consists of a number of downloadable conversational dialogues. Topics covered include making friends, apartment hunting and visiting a library.

"Impact! Online" was created as the result of a collaboration between the University of Illinois College of Education and Passport Educational Publishing. This site takes the form of an interactive, on-line news magazine. Source articles cover a wide range of topics including social issues, world news and sports. Potentially difficult words are highlighted and a learner may click on such a word and follow a hypertext link to an explanatory page. A number of links feature downloadable audio files. The owners of this site also maintain an email mailing list.

"On-line English Grammar" provides exactly what its title implies. The following areas of usage are covered: adjectives, determiners, adverbs, possessives, nouns, pronouns and verbs. Useful features of this site include an on-line grammar clinic in which learners may submit grammar queries, an FAQ (frequently asked question) page and site based search engine.

"Foreign Languages for Travelers" supplies audio downloads of basic vocabulary and useful sentences related to traveling. Downloads are available in 32 languages and in a number of cases users may download audio files in English and the language chosen. In addition the site provides hypertext links to bilingual on line dictionaries, WWW-based travel guides and cultural information relevant to the country selected. This site is best accessed by browsers that support 
forms; however, a text-only version is available.

The Cyberhandbook of English originates from the University of Aizu in Japan. This site is designed to address the writing needs of learners and focuses on vocabulary use, grammar, mechanics, presentational techniques and technical writing. The site is characterized by the extensive use of context based examples.

The purpose of the simulation-based Business Meetings is to guide learners through a hypertext based decision maze. Learners are presented with a problem and a number of possible solutions. Selection of an answer leads to linked pages and further questions. The help section of this site features teacher and student instruction pages, and a function and structure list. An on-line vocabulary list provides downloadable audio files (suitable for Windows machines) of target vocabulary. An on-line comprehension test is also available. This site is best accessed through Netscape (version 2.0 or above).

Conclusion Technology in the field of distance learning is advancing rapidly, although it is still in the early stages of its development. The next few years will see the increasing utilization of advanced "streaming" and plug-in software that will provide both audio and video on demand as central features of many multimedia language learning web sites. The challenge for the future lies in the manner in which we as educators harness the potential of Web-based learning to meet the needs of effective pedagogy.

Works Cited Duber, J. (1996). Cutting Edge CALL Resources, http:// www.+chorus.cycor.ca/Duber/m004d.html (12 Feb. 1997).

Harris, M. \& Taylor, D. (1997). The Purdue University OnLine Writing Lab (OWL), http://owl.english.purdue. edu (12 Feb. 1997).

Hart, R. C \& Li, R. C. (1996). "What Can the World Wide Web Offer ESL Teachers?" TESOL Journal, Winter.

Hegelheimer, V. \& Zhao, Y. Li, R. C. (1995). EX*CHANGE, http://deil.lang.uiuc.edu/exchange/ (25 Feb. 1997).

Hughes, A. (1996). On-Line English Grammar, http:// www.edunet.com/english/grammar/index.html (20 Feb. 1997).

Li, R. C. (Ed.), (1996). Learning Oral English On Line, http:// www.lang.uiuc.edu/r-li5/book/ (24 Feb. 1997).

Martin, M. C. (1994). Foreign Language for Travelers, http:/ /www.travlang.com/languages (20 Feb. 1997). 


\section{Lab Notes}

Orr, T. (1996). Cyberhandbook of English, http://www.uaizu.ac.jp/ t-orr/CybHandbk.html (16 Feb. 1997).

Page, L. \& Sugimoto, T. (1995). Impact! Online, http:/l www.ed.uiuc.edu/impact/ (19 Feb. 1997).

Shetzer, H. (1995). "EX*CHANGE: Electronic Xcross Cultural Hypertext Academy of Non-native Gatherings in English." In M. Warschauer (Ed.), Virtual Connections. Honolulu, Hawaii: University of Hawaii Press.

Vallance, M. (1996). Business Meetings, http://www.stir.ac.ukJ epd/celt/staff/higdox/Vallance/Diss/fp.htm (17 Feb. 1997).

Vilmi, R. (1993). HUT Internet Writing Project, http:// www.hut.fi/ rvilmi/Project (Feb. 21 1997).

Mark Peterson is Lecturer at the Japan Advanced Institute of Science and Technology, Ishikawa Prefecture, Japan. 
The Thirty-Third Annual Convention and Exposition Teachers of English to Speakers of Other Languages, Inc. New York, New York

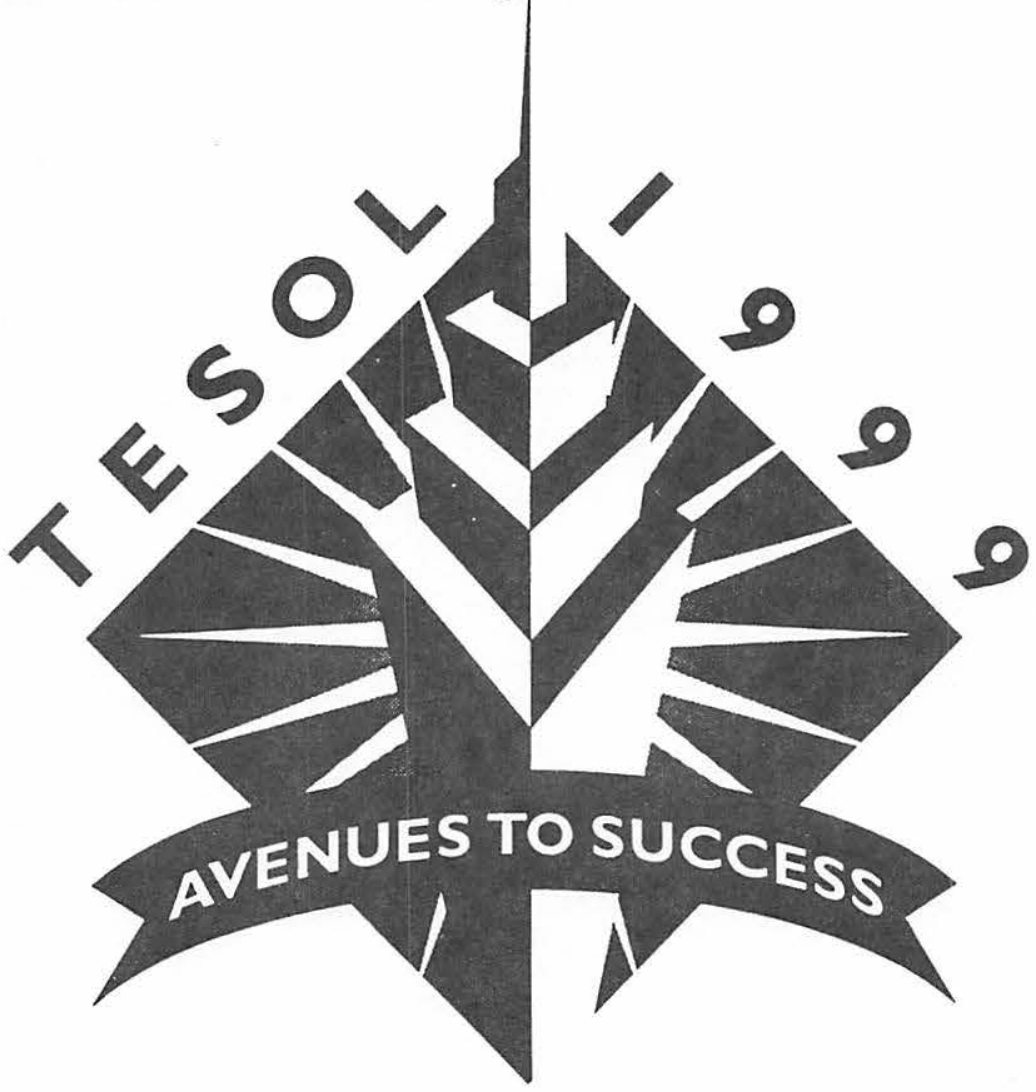

\section{March 9-13, 1999}

For more information please contact: TESOL Conventions Department, 1600 Cameron Street, Suite 300. Alexandria, Virginia 22314-2751 USA Telephone 703-836-0774 • Fax 703-836-7864 E-mail conv@tesol.edu • http://www.tesol.edu/ 